\title{
Using home-laboratory kits to teach general chemistry
}

\author{
Dietmar Kennepohl
}

\author{
Athabasca University, Athabasca, Alberta, CanadaT9S 3A3 \\ e-mail: dietmark@athabascau.ca
}

Received 18 April 2007, accepted 8 June 2007

\begin{abstract}
University-level chemistry courses that contain a substantial laboratory component have always been a challenge to deliver effectively through distance education. One potential solution is to enable students to carry out real experiments in the home environment. This not only raises issues of logistics and safety, but also the fundamental question of whether an equivalent learning experience could be achieved with home laboratories. Athabasca University, Canada's Open University, has been successfully running chemistry courses for almost three decades. The migration from traditional supervised laboratories to home-study experiments over a fifteen year period in a general chemistry course is described. The study examines both student experience using the home-study laboratory kits, and their actual performance. Student grades in the course essentially remain the same as supervised laboratories are replaced by home-study laboratories, while at the same time offering the student increased access and flexibility. Furthermore, bringing experiments into a home environment contextualizes learning for the student and raises the possibility of incorporating the home-study laboratory experience, in whole or in part, into traditional general chemistry course offered on campus. [Chem. Educ. Res. Pract., 2007, 8 (3), 337346.]
\end{abstract}

Keywords: general chemistry, laboratory, home-study, home-laboratory kits, distance education, educational freedom, contextualized learning

\section{Background}

While laboratory work is at the heart of many good chemistry courses, it is also one of the most difficult components to deliver effectively at a distance. In developing laboratory components for distance education one invariably faces the larger question of why we, as chemical educators, actually require laboratory work. What are we trying to achieve? Is it a right of passage for chemistry students? Is it a historical tour of chemistry past? For a distance educator it would certainly be easier to deliver only the content and theory without requiring the practical work. It would also seem that, given the choice, chemistry students might choose to avoid the laboratory experience. Byers observed that many students, essentially motivated by marks, are uncomfortable doing practical work, and view it as yet another form of assessment (Byers, 2002).The rationale for having practical work in chemistry, the role of the teaching laboratory and its changing nature has been discussed and will continue to be discussed at great length within the chemical education community (Kember, 1982; Lagowski, 1989; Bennett and O’Neale, 1998). The design of any laboratory component, including home-study experiments, is often done to meet a variety of aims. The most general aim is the reinforcement of course concepts through illustration and making it real for the student. This is followed by the development of techniques and skills in the student that are either cognitive or practical in nature. It could include skills such as physical manipulations, observations, problem solving, data handling, interpretation of results, time management, and 
dealing with errors to name just a few. Finally, many teachers cite the laboratory environment as an opportunity or vehicle to inspire students and make chemistry impressive enough to remember. The approach described by those who have designed and used home-study laboratories will certainly be familiar to educators creating equivalent on-campus experiments (Rudd, 1994; Ross and Scanlon, 1995; Boschmann, 2003; Casanova et al., 2006).

Although chemistry home-study laboratories have many of the aims, concerns, and approaches in common with traditional laboratories, there are notable differences. The first and most obvious is that they offer the learner autonomy in space and time. Educators such as Moore and Paulsen argue that a high level of freedom and individual choice is crucial in distance education (Moore, 1983; Paulsen, 1993). Distance learners perceive themselves as self-directing individuals who are seeking control of their own learning outcomes. The assumption is that they are highly motivated, so course design incorporating a high degree of student freedom is desirable. While home-study laboratories achieve this aim, it should be remembered that students enjoying the freedom of carrying out experiments individually are also isolated from their peers. Apart from the feeling of loneliness and seclusion, the lack of student-student interaction does raise the question of whether this laboratory learning experience is being adversely affected.

This leads to the second notable difference. Of the three common types of interaction involving students described in the literature (student-student; student-teacher; studentcontent), the home-study laboratories possess a strong student-content component. There is some student-teacher interaction with tutor e-mail and phone communication, but no real student-student interaction. Anderson recently proposed an equivalency theorem, which suggests that one form of interaction can be effectively substituted for another (Anderson, 2003). In essence, so long as there is at least one mode of interaction present in the three legs of this interaction tripod, deep and meaningful formal learning is supported.

The third notable difference that should be considered is the context of the home-study laboratory itself. We recognize that not only what we teach but how we teach is affected by our chemistry environment and culture. Our teaching and learning approach is different from other disciplines - even other disciplines in science. The importance of chemical philosophy in chemical education has been well identified and discussed in the literature (Scerri, 2001; Erduran et al., 2007). The teaching laboratory experience is certainly an important vehicle in conveying how chemists think and operate. The home-study laboratory kits will also do this, but it differs from the residential laboratory in that it further contextualizes learning for the student. The experiments are brought right into the home and chemistry is no longer something that is done only in the laboratory.

This work examines student experience and performance over sixteen years as we have incrementally replaced traditional supervised experiments with home-study experiments.

\section{Methodology}

This study is focussed on the laboratory component of the course Chemical Principles I (CHEM 217), which represents the first half year of general university chemistry. The intent was to determine whether CHEM 217 students could attain an equivalent learning experience with home-study experiments compared with supervised laboratory work. Athabasca University chemistry course delivery of CHEM 217 including the course development team, course materials, importance of the laboratory component, and the role of the telephone tutor, has been previously presented in detail (Kennepohl and Last, 1998). The important features to remember with delivery of chemistry courses at Athabasca University are:

1. There is continuous, year-round enrollment. 
2. Except for some supervised laboratory sessions (found only in older versions of CHEM 217), the course is self-paced.

3. Although there are online components and resources, the courses are mainly print-based materials that wrap around (integrate with) commercially available textbooks.

4. Students receive tutor support by telephone and e-mail.

5. Telephone tutors mark assignments and laboratory reports giving detailed feedback.

6. The course has mostly visiting students from other universities or students wishing to attain pre-requisites for professional programs (e.g. medicine, dentistry, pharmacy). Only 6\% are program students with Athabasca University.

Originally, the CHEM 217 laboratory component was only offered as paced face-to-face instruction in supervised laboratories on campus or at regional centres. Several years ago a kitchen chemistry component and then a home-study kit was introduced so that students could complete half of the experiments at home. Students in the current version of CHEM 217 can complete the course by doing the laboratory component completely at home with a homestudy laboratory kit ordered from the university. At the end of their CHEM 217 course the students working entirely at home were surveyed and asked about their laboratory experience and their background. The performance of students in the laboratory component, assignments, and examinations was also tracked over several years through all the different versions of the course. A simple t-test was employed to determine if there were significant differences in performance of groups of students as more home-study laboratories were introduced.

\section{Kit development}

We originally became involved with home-study laboratories through the incorporation of kitchen chemistry experiments into the regular laboratory component of the course. To overcome some of the students' diffidence in coming out to the first face-to-face laboratory session, we made their first experiment one that could be done at home using simple household equipment and chemicals. The idea was to engage students with laboratory work early enough in the course to encourage attendance at supervised sessions. The results of this pilot were reported elsewhere (Kennepohl, 2000). We then developed a series of four homestudy experiments that were much more sophisticated than the kitchen chemistry experiments. Students would now carry out the kitchen chemistry as well as home-study experiments using the kit. They would then attend another 16 hours of face-to-face laboratories. Detailed descriptions of these experiments, as well as the equipment and chemicals used, can be found elsewhere (Kennepohl, 1996). Students felt that unlike the kitchen chemistry experiments, these new home-study experiments were of university quality.

In an effort to engage students further in the laboratory component of CHEM 217 we increased flexibility and access for the students by developing a home-study kit that would allow all laboratory work to be done independently at home. A major concern during the development of these home-study kits was providing portability and safety, while still achieving university-level quality in the experiments. What that quality actually means and how it is perceived is certainly debatable. In the end, a vital part of achieving that quality meant the incorporation of appropriate quantitative experiments, which in turn often comes down to providing the student with a suitable laboratory balance. It was a challenge to find a balance that was inexpensive, precise ( $\pm 0.01 \mathrm{~g}$ ), and robust enough to be shipped in the home-study kit. However, the balance was seen to be an important component of the kit and certainly differentiates this kit from others that contain primarily qualitative experiments.

We converted all the face-to-face experiments and added them to the existing home-study kit. These included mass and volume measurement, use of a simple spectrophotometer, acidbase titrations, determining the universal gas constant, and determining the stoichiometry of a 
reaction. In each experiment the home-laboratory kit provided the students with the necessary chemicals and equipment

(http://science.pc.athabascau.ca/chem217.nsf/experiments2?OpenPage) . We also developed an instructional CD to accompany the kit, which showed video clips of good safety practices, experimental set up, and techniques required to carry out the experiments.

\section{Laboratory’ program}

- In the first experiment the students learn how to calibrate and use a general pan balance. They learn the technique of weighing by difference and determine the density of water. They also calibrate a volumetric pipette using mass and density.

- In the second experiment students determine the amount of acetylsalicylic acid in a commercial ASA tablet using spectrophotometry. The tablet is hydrolyzed with $\mathrm{NaOH}$, the acetylsalicylic acid is complexed with iron(III) chloride, and then analyzed in a simple spectrophotometer. The resulting absorption is compared to absorptions of standard acetylsalicylic acid solutions.

- In the third experiment students again determine the amount of acetylsalicylic acid in a commercial ASA tablet but using acid-base chemistry. The tablet is hydrolyzed with a known amount of $\mathrm{NaOH}$ and the excess $\mathrm{NaOH}$ left over after the reaction is titrated with $\mathrm{HCl}$ standard. The calculated amount of acetylsalicylic acid present is compared with the value obtained spectrophotometrically in the previous experiment.

- The aim of the fourth experiment is to determine the universal gas constant (R). Nitrogen gas is chemically generated and trapped over water. Assuming the ideal gas law, the student calculates $\mathrm{R}$ and compares the value obtained with the literature value.

- Finally, the last experiment illustrates how the determination of the stoichiometry of a reaction can be determined empirically using a redox titration. Iodine produced in the reaction is titrated with sodium thiosulphate and calculations can then be done to determine the ratio of iodate to iodine in the overall reaction. This is the last experiment in the course and differs from the other experiments, because no experimental procedure is given to the student. After reading the theory and background information on the reactions, students are given the objective of experimentally finding the stoichiometry of a reaction. They must develop their own written procedure and have it approved by their tutor before proceeding.

Each kit costs approximately \$800 CAN (\$ 680 US, euro 500, £350 GB) and contains the essential chemicals and equipment for all the experiments. However, students are expected to provide some common household ingredients and equipment such as a stove top or tap water. The kit dimensions are $41 \times 46 \times 47 \mathrm{~cm}$ and it weighs $5.4 \mathrm{~kg}$. Once registered in the chemistry course, a student can order a home-laboratory kit online to use for a period of two months. The kit is shipped cost-free to the student and the university also covers the return shipping costs. There is no kit deposit required, but grades are withheld until the kits are returned. The non-return rate of kits is relatively low (1.0\%). Once a kit is returned, staff check it over to replace consumables and any damaged items before sending it out to the next student.

\section{Results}

The survey data of students taking the full home-study laboratories were compared with previous students taking half the laboratories at home and those only doing one kitchen chemistry experiment at home (Table 1). Examining student profiles, the average age of the students (30 years) was slightly higher, but essentially the same (29 and 28 years) as in previous surveys. The number of students with absolutely no post-secondary experience (7\%) 
was also slightly higher, but essentially the same (5 and 6\%). However, the average time since a student has done a laboratory course (4.7 years) was slightly lower than the other groups (5.7 and 6.3 years). There were two major differences observed in the profile of students who did the laboratories entirely at home. First, the proportion of female students (65\%) had grown significantly from earlier surveys (41 and 48\%). Secondly, there were substantially fewer students with completed university degrees (39\%) or college diplomas (22\%) than those who had university degrees (50 and 48\%) or college diplomas (45 and $45 \%$ ) in former survey groups. The increase in the number of female students parallels the trend seen at other Canadian universities and has been generally attributed to a strong economy and employment opportunities decreasing male participation in post-secondary education. We cannot interpret the observation of the decrease in proportion of previous degrees or diplomas held by students.

Table 1: Summary of CHEM 217 student surveys of the Home-Study Experiments.

\begin{tabular}{|l|c|c|c|}
\hline & Full Home Lab & Half Home Lab $^{\dagger}$ & Kitchen Chemistry $^{\dagger}$ \\
\hline Female & $65 \%$ & $41 \%$ & $48 \%$ \\
\hline Male & $35 \%$ & $59 \%$ & $52 \%$ \\
\hline Average Age & 30 years & 28 years & 29 years \\
\hline University degree & $39 \%$ & $50 \%$ & $48 \%$ \\
\hline College diploma & $22 \%$ & $45 \%$ & $45 \%$ \\
\hline No post-secondary experience & $7 \%$ & $5 \%$ & $6 \%$ \\
\hline $\begin{array}{l}\text { Average time since last chemistry } \\
\text { laboratory experience }\end{array}$ & 6.7 years & Not available & Not available \\
\hline $\begin{array}{l}\text { Average time since last science } \\
\text { laboratory experience }\end{array}$ & 4.7 years & 5.7 years & 6.3 years \\
\hline University quality achieved & $83 \%$ & $85 \%$ & No (anecdotal) \\
\hline $\begin{array}{l}\text { Want home-study option for other } \\
\text { science labs }\end{array}$ & $78 \%$ & $83 \%$ & $85 \%$ \\
\hline Instructions easy to follow* & 3.9 & 4.5 & 4.3 \\
\hline Easy to obtain all equipment* & 4.5 & 4.1 & 4.0 \\
\hline Experiments interesting* & 4.2 & 4.0 & 3.1 \\
\hline Course material reinforced* & 4.1 & 4.0 & 3.0 \\
\hline Number of responses & 182 & 218 & 59 \\
\hline
\end{tabular}

* Students were asked to rate on a five-point Likert scale.

† Previously reported data (Kennepohl 2000)

Many of the qualitative ratings compared between the full and half home-study laboratory students on the home-study laboratory kit were very similar (Table 1). Students felt that university quality was achieved (83 versus $85 \%$ ), that the experiments were interesting (4.2 versus 4.0 ), and that course material was reinforced (4.1 versus 4.0$)$. The ease of finding equipment was rated higher for the full kit (4.5 versus 4.1 ), but there were lower scores for ease of experiment instructions (3.9 versus 4.5) and desire to want more home-study laboratories (78 versus $83 \%$ ). We feel the difference in the last two categories is small and might be a reflection of the increased sophistication of added experiments. Still, there is an overall positive student satisfaction.

There was an opportunity in the student survey to comment freely on the laboratories. The most common remarks were about the flexibility offered by the home-study kits, as well as the positive response to the accompanying instructional CD. Several students also commented that they would involve their family in carrying out the experiments at home and seemed quite enthusiastic about doing so. This was an unexpected result, and although anecdotal information, it underscores the importance of viewing these laboratories in the context of the home environment. 
Of more interest is the actual student performance. Student performance in CHEM 217 with respect to assignments, examinations, and laboratory component is summarized in Table 2. The data corresponds to students who completed the course from January 1990 to July 2006. The course version (numbered 1 through 6) represents major course revisions to the theory part of the course. We see that the composite final grade has stayed in the $75-80 \%$ range over the last fifteen years. Students tend to score highest on their assignments and laboratory components, with assignments usually being slightly higher. As a group they score lower on the examinations, where the final examination is always lower than the midterm examination. We see this same general pattern in other chemistry courses at the university.

As we change course version (1 through 6 ) there are some slight variations in final grade. Versions 1 through 4 represent change in edition of the same text book. Versions 5 and 6 are two editions of a different text book. The overall pattern seems to start with a composite grade of approximately $76 \%$, then moves to about $80 \%$ (Versions $2-4$ ), and finally drops back again at the end to $76 \%$ (Versions 5 and 6). Superimposed on the particular course versions are changes to the laboratory component of the course which occurs part way through Version 4 (introduction of 50\% home-study laboratories) and part way through Version 5 (introduction of $100 \%$ home-study laboratories). These two transition points represent change to only the laboratory portion of the course and are of most interest to this study.

Within Version 4 the average grade values for each component of the course appear slightly greater in the group having $50 \%$ home-study laboratories. However, a simple t-test confirms that the values are statistically the same within each course component (p values > 0.05 ranging $0.16-0.79$ ). Within Version 5 the transition to $100 \%$ home-study show more substantial grade increases in each course component. Indeed t-test confirms that (with the exception of the assignment component, $\mathrm{p}$ value $=0.054$ ) the values are statistically different (p values $<0.05$ ranging 0.004-0.026).

Table 2: CHEM 217 Student Performance (1990 to 2006).

\begin{tabular}{|c|c|c|c|c|c|c|c|c|}
\hline \multirow{2}{*}{$\begin{array}{c}\text { Course version } \\
\begin{array}{c}\text { Home-study laboratory } \\
\text { component }\end{array} \\
\end{array}$} & 1 & 2 & 3 & & 4 & & 5 & 6 \\
\hline & \multicolumn{4}{|c|}{ None } & \multicolumn{2}{|c|}{ Half } & \multicolumn{2}{|c|}{ Full } \\
\hline Number of students & 52 & 49 & 19 & 15 & 124 & 222 & 60 & 194 \\
\hline Assignments (\%) ${ }^{\dagger}$ & 85.8 & 85.7 & 80.5 & 84.0 & 86.5 & 85.2 & 87.5 & 88.9 \\
\hline Midterm exam (\%) ${ }^{\dagger}$ & 74.7 & 80.6 & 84.4 & 78.0 & 83.6 & 71.4 & 75.3 & 74.4 \\
\hline Final exam $(\%)^{\dagger}$ & 68.2 & 76.0 & 75.5 & 73.9 & 74.9 & 67.5 & 71.9 & 68.8 \\
\hline Laboratories $(\%)^{\dagger}$ & 78.8 & 81.6 & 80.7 & 80.4 & 82.5 & 83.5 & 87.5 & 87.8 \\
\hline Composite $(\%)^{*}$ & 75.8 & 80.1 & 79.6 & 78.4 & 80.4 & 74.7 & 77.7 & 76.6 \\
\hline
\end{tabular}

$†$ Percent values truncated to one decimal place.

* Composite grade is a weighted average equal to $20 \%$ assignments plus $20 \%$ midterm exam plus $20 \%$ lab plus $40 \%$ final exam from original values.

\section{Discussion}

The concept of freedom and individual choice for distance learners is an important driver for success. Yet designing genuinely independent and self-paced chemistry courses for the individual learner is challenging, especially when a laboratory component is required. There have been numerous approaches to address this, including using regional laboratory sites, concentrating laboratory sessions, offering flexible hours (weekends and evenings), as well as employing computer simulations and remote laboratories. The home-study laboratory kit 
offers another approach to attaining access, flexibility and freedom for the distance learner. The student surveys certainly support this view from the students' perspective. However, it is more than opinion. Many students come to CHEM 217 and other distance courses, because the more traditional routes to access an equivalent course are just not readily available to them.

Although one can argue that increased student freedom and individual choice may motivate learning or just plain make it possible to access the opportunity to learn in the first place, it does not necessarily follow that learning equivalent to the traditional face-to-face can be achieved. The potential concern with the home-study laboratory is that there is no studentstudent interaction and there is no physical presence of a laboratory instructor. The course tutor is available remotely via telephone or e-mail, and so the student-instructor interaction is certainly less than one would find in a traditional teaching laboratory. It is a potential concern because epistemological assumptions are such that a high value is placed on the role of human interaction in education and learning. Indeed, human interaction can and does lead to both formal and informal learning. However, we know that other forms of interaction can also lead to learning.

The main interface in the home-study laboratory is the student-content interaction followed by limited student-instructor interaction. In this regard, one vital feature of the kit that cannot be over emphasized is the accompanying instructional CD containing indexed video clips. Although all the safety instructions and information to carry out the experiments are available in the printed laboratory manual, the CD is an effective medium to emphasize safety and demonstrate experimental techniques. It provides a closer connection between the student and the content by reinforcing the text in the laboratory manual, making the experiments less daunting, giving the students more confidence in carrying out the experiments, and hopefully, also inspiring them to start the experiments in the first place. In addition, the use of video clips of actual laboratory instructors talking to the students provides a type of simulated human interaction, albeit one-way. Effectively, some aspects of the student interaction with the instructor migrate to interaction with the content. The comment section on the student survey did reveal the existence of another type of interaction. In some cases students would involve their families in carrying out experiments at home. This suggests that students working at home might also make use of student-family (or studentroom mate) interactions in their learning process, in addition to the types of interactions already discussed. However, it is unlikely that the family or room mate interactions would focus directly on the course material to the same degree as interactions with an instructor or with fellow students. It is unclear to what degree family or room mate interactions occur or what their exact role is in the learning process. Presumably that interaction may serve more to support, encourage, and contextualize rather than offer access to content and experience. This area would need further study.

Even though grades slightly increase with the home-study students, both the survey and the course performance statistics indicate that the CHEM 217 home-study laboratory mode is essentially equivalent to our earlier supervised laboratories. Some other studies comparing student performance between home-study and on-campus laboratories in general chemistry demonstrate that home-study students perform better (Boschmann, 2003; Casanova et al., 2006). The stronger performance by distance students has been attributed to student maturity in at least one study (Boschmann, 2003). It should be noted that the distance students in all these studies (including this work) tend, as a group, to be more mature, possess more experience, and have more commitments outside of their studies at university. The increased degree of these additional commitments such as family or job would certainly explain the pursuit of the access and flexibility distance learning would offer. This in itself is not a new observation, but it does underline the fact that these more mature students will have a greater 
tendency to self select for distance education than the typical 18-19 year old coming straight from high school. In contrast to our study, the studies carried out at dual mode institutions allow for that self selection. That comparison of non-equivalent groups raises the question whether the learning method or the make up of group itself is driving the difference in performance (Casanova et al., 2006). In this study there is not as great a difference in the student profile between those that that have done fully supervised laboratories or either the half or full home-study laboratories. Presumably any differences between the groups would more likely be due to the environment of the course itself rather than the background of the group.

The learning experience between home-study and the supervised laboratories is not identical, but undoubtedly equivalent. This is consistent with Anderson's equivalency theorem and shows that this mix works well in this particular case (Anderson, 2003). The learning experience in the home-study laboratory is different, but is it merely a substitute for supervised laboratories when students cannot attend? One notable benefit the home-study laboratory does have is the potential to contextualize learning for the student. General chemistry deals with a lot of abstract ideas and symbol manipulation, which can be barrier to a learner new to world of chemistry. The laboratory component offers an opportunity to make some of those concepts real for the student. However, the laboratory environment with its specialized equipment, procedures and particular hazards can possess its own barriers to effective learning. Some students are downright intimidated when working in a formal laboratory environment. Over fifteen years ago in our investigation of the low participation rate in CHEM 217 supervised laboratories, our students reported a lack of confidence and reluctance in attending initial sessions. This was not surprising as our students tended to be older and had on average not been in a laboratory for about six years (see Table 1). This prompted our development of the kitchen chemistry experiments, which eventually lead to a full home-study laboratory. Bringing those experiments into a home situation allows the student to work in more familiar surroundings. In some cases the experiment itself may make use of techniques and equipment found in the home. For example, instead of demonstrating boiling point elevation by using a beaker of water and Bunsen burner, a cooking pot of water and stovetop is used. The idea of contextualizing the laboratory in this manner is that intimidation is reduced; it affords the opportunity to use what students know already, and should result in more effective learning. In addition, the strong underlying message given to the student is that chemistry exists outside the laboratory.

At this point it may be worthwhile asking if there is any application of our home-study laboratory experience for the more traditional general chemistry course on campus. The trend in recent years has been the exploration of blended learning in which on-line and multimedia resources supplement face-to-face teaching. Institutions delivering supervised laboratory sessions are also under increasing financial and regulatory pressures to minimize the practical aspect of their chemistry courses. Many are turning to virtual laboratories to either replace or supplement current laboratories (Kennepohl, 2001). Computer simulations can offer some learning opportunities that real laboratories alone cannot, but conversely, they cannot replace the real experience in all cases. It is the innovative combination of the virtual and real laboratories that seems to offer the potential for effective and meaningful learning. In a similar fashion, a home-study laboratory (whether used in whole or in part) would not only address institutional challenges, but offer an extra dimension of learning for residential chemistry students who might respond well to and benefit from some independence and exploring chemistry outside the traditional laboratory. 


\section{Conclusions}

We feel that a strong laboratory component is vital to our general chemistry course and have designed a home-study laboratory for our students studying at a distance. Our conclusions are summarized as follows:

1. The home-study kits developed are safe, portable, easy to use, and inexpensive to maintain.

2. The independence and freedom that a home-study laboratory offers is vital to success of our students taking the course at a distance.

3. Student survey results and actual student performance indicate that the home-study laboratory experience is equivalent to that found in supervised on-campus laboratories.

4. Bringing experiments into the home contextualizes the learning, and demonstrates that chemistry can be done outside a formal laboratory environment.

5. There is potential application for home-study laboratories at residential institutions.

\section{Acknowledgements}

The author would like to thank Neil Sexton for the home-study kit information and statistics; Rick Powell and Tamara Jackson for the statistical data on student performance in AU chemistry courses; and Angela Thomas for assembling the student responses from the survey.

\section{References}

Anderson T., (2003), Getting the mix right again: an updated and theoretical rationale for interaction, International Review of Research in Distance Education, 4,

http://www.irrodl.org/index.php/irrodl/article/view/149/230 (online journal, ISSN: 1492-3831).

Bennett S.W. and O’Neale K., (1998), Skills development and practical work in chemistry, University Chemistry Education, 2, 58-62.

Boschmann E., (2003), Teaching chemistry via distance education, Journal of Chemical Education, 80, 704-708.

Byers W., (2002), Promoting active learning through small group laboratory classes, University Chemistry Education, 6, 28-34.

Casanova R.S., Civelli J.L., Kimbrough D.R., Heath B.P. and Reeves J.H., (2006), Distance learning: a viable alternative to the conventional lecture-lab format in general chemistry, Journal of Chemical Education, 83, 501-507.

Erduran S., Aduriz-Bravo A. and Mamlok-Naaman R., (2007), Developing epistemologically empowered teachers: examining the role of philosophy of chemistry in teacher education, Science \& Education, (In Press).

Kember D., (1982), External science courses: the practicals problem, Distance Education, 3, 207-225.

Kennepohl D., (1996), Home-study microlabs, Journal of Chemical Education, 73, 938-939.

Kennepohl D. and Last A.M., (1998), Going the distance in Canada, Education in Chemistry, 35, 1920.

Kennepohl D., (2000), Microscaled Laboratories for home study: a Canadian solution, Chemeda: The Australian Journal of Chemical Education, 54/55/56, 25-31.

Kennepohl D., (2001), Using computer simulations to supplement teaching laboratories in chemistry for distance delivery, Journal of Distance Education, 16, 58-65.

Lagowski J.J., (1989), Reformatting the laboratory, Journal of Chemical Education, 66, 12-14.

Moore M.G., (1983), On a theory of independent study. In Sewart D., Keegan D. and Holmberg, B. (Eds.) Distance education: international perspectives, Croom Helm/St. Martin's Press, London/New York, 68-94.

Paulsen M.F., (1993), The hexagon of cooperative freedom: a distance education theory attuned to computer conferencing, DEOS - The Distance Education Online Symposium, 3, http://www.ed.psu.edu/acsde/deos/deosnews/deosnews3_2.asp (online journal, ISSN: 1062-9416). 
Ross S. and Scanlon E., (1995), Open science: distance teaching and open learning of science subjects, Paul Chapman Publishing Ltd., Great Britain, 137-145.

Rudd V., (1994), Happy birthday to yOU, Education in Chemistry, 31, 87.

Scerri E.R., (2001), The new philosophy of chemistry and its relevance to chemical education, Chemistry Education: Research and Practice in Europe, 2, 165-170. 